\title{
LAS NOCIONES NORMATIVAS DE JUSTICIA Y GOBIERNO EN LA MINERÍA MEXICANA DEL SIGLO XVIII AL XIX
}

Oriel Gómez Mendoza ${ }^{1}$

\begin{abstract}
Resumen: La separación de las funciones de gobierno y justicia en materia minera fue posible a instancias del discurso liberal y a una serie de procesos de secularización que pretendieron enterrar a un llamado "antiguo régimen", aunque éste resistió prácticamente durante todo el siglo XIX. La transición de ese mundo viejo a uno nuevo es un proceso de múltiples dimensiones, que va del modelo despótico ilustrado al criollismo, pasando por las juntas patrióticas, la independencia, la república, las reformas y finalmente el porfiriato. Todo ello terminó por dar a la administración de justicia y a las funciones gubernativas, en la actividad minera, calidad o calidades diferentes, sobre todo ante la discusión de la base soberana que habría de seguir, primero, la colonia hispánica, la nación recién independizada o el nuevo Estado-nación mexicano. Por tanto, el texto que se presenta da seguimiento a esas inquietudes a través de las normatividades en materia minera.
\end{abstract}

Palabras clave: normativas, minería, justicia y gobierno, México.

1 Profesor e Investigador de la Facultad de Historia de la Universidad Michoacana de San Nicolás de Hidalgo, México; perteneciente al cuerpo académico de Historia de México (CA-48). Proyecto financiado por PROMEP con identificación PTC-158. Correo electrónico: orielgm@ yahoo.com.mx. 


\title{
A NORMATIVE NOTION OF JUSTICE AND GOVERMENT IN MEXICAN MINING IN THE XVIII AND XIX CENTURIES
}

\begin{abstract}
The division of government and justice in what concerns to mining in Mexico, was only possible due to two main things: the liberal discourse and a series of processes tending to burry the so called "ancient regime", despite the efforts from the latter to avoid disappearance during the XIX century. The transition, from that old order to this new one, is a process of multiple dimensions, starting from the despotic model and going through to the ideas of the creoles, and also considering the patriotic meetings, the independence, the republic, the reforms and finally the Porfirio Diaz regime.

All the above led the justice administration and the function of the government, in the matter of mining, to a certain differentiation between their responsibilities, especially about the concept of sovereignty the new born country should follow.

Therefore, this paper examines those questions following the norms established in mining.
\end{abstract}

KEY WORDS: Normative notion, Mining, Justice and Government, Mexico.

Recibido: agosto 2009

Aceptado: enero 2011

\section{Introducción}

$\mathrm{D}$ esde Tocqueville hasta Xavier Guerra, entre muchos otros, se ha hecho alusión a un "antiguo régimen" y a la ubicua contraparte de lo "moderno", diada a partir de la cual se analizan sociedades y contextos históricos distintos, se calibran modos de vida y aspiraciones sociales vistos a través de esos dos lentes que constituyen o adjetivan lo viejo como arcaico y lo moderno como deseable. Mucha tinta ha corrido pues en torno a esa discusión, no obstante, me parece no se han agotado las temáticas ni las variables de análisis al respecto $y$, por el contrario, el avance de la historiografía ha abierto nuevas preguntas.

Para quienes somos neófitos en semejantes temas no nos queda sino hacernos preguntas generales a propósito de ello. La primera de ellas es sin duda cómo se han establecido los valores necesarios para hablar de "antiguo régimen" y sus límites de aplicación, lo cual conlleva pues a la comprensión de cierta postura metodológica subyacente a estos intereses. Una segunda interrogante consiste en responderse en qué momento se estructura un paradigma social que se nombra a sí mismo diferente de un orden antecesor, al cual llama "antiguo" y le confiere, en ese momento, una carga ciertamente peyorativa, pero no 
porque con ello necesariamente define la cosa por sus valores inherentes, sino por lo que no es o lo que no debería ser. La tercera interrogante de carácter general solo es posible si asumimos que se tiene cierto conocimiento de las dos primeras interrogantes; en esa circunstancia pues hay que preguntarnos de qué manera ocurrió el cambio de antiguo régimen hacia uno nuevo, si se tiene que ver como un rompimiento drástico - probablemente una revolución- o como una transición lenta. Este es el asunto de la Historia.

Quiero entonces anticipar mi conclusión, aunque me aparte con ello de la ortodoxia: creo que hemos insistido en demasía sobre las rupturas y los cambios en los procesos de formación del Estado-nación moderno. Por el contrario, hemos tratado de obliterar el hecho de que hay una enorme y consistente cantidad de permanencias en las realidades nacionales, que se constituyen como resistencias al cambio. Por ello, quisiera plantear que un panorama más completo y que estructura un modelo operativo de mayor visión debe atender tanto a la ruptura como a la permanencia, sin separarlas, en la misma dimensión; tal vez con ello afine la ya vieja idea que alguna vez lanzó Antonio Annino en términos de diferenciar el pacto de la norma ${ }^{2}$, uno como estructura tradicional y el otro como una formal, y cuya comprensión conjunta retrataba a la sociedad mexicana.

En esa perspectiva, el objeto de estas líneas descansa en la posibilidad de explicar por qué existió un marcado interés por normar la actividad minera en México, prácticamente desde el inicio de la vida colonial; sin embargo, la tarea rebasa las posibilidades de un artículo, así que me referiré solamente a una serie de consideraciones sobre rupturas y permanencias en las normatividades existentes, pero con el énfasis particular sobre dos aspectos básicos para el buen funcionamiento de la actividad: me refiero, en primera instancia, a las cuestiones dedicadas al gobierno, entendido como la capacidad de generar normas para el buen funcionamiento de una actividad; la impartición de justicia será el otro aspecto a contemplar y con ello referiré a la solución de conflictos en el marco de las normas establecidas por el gobierno.

Quiero advertir que este trabajo tiene dos niveles: se nutre, obviamente, primero de los diferentes cuerpos normativos en materia minera; en segunda instancia, refiere a una revisión historiográfica que contempla la evolución del derecho minero y sus instituciones, pero no se incluyeron documentos referentes a litigios mineros, de tal manera que no es un estudio sobre jurisprudencia o la

2 Annino, Antonio, "El pacto y la norma: los orígenes de la legalidad oligárquica en México", Historias, ํ5, Revista del INAH, 1985. 
práctica contenciosa, ni la actividad de impartir justicia. Con esta advertencia apunto que, en realidad, los "textos culturales" son las propias normatividades.

Para dar seguimiento a este trabajo, en primera instancia se tomaron Los Comentarios a las Ordenanzas de Minas, de Francisco Xavier Gamboa, libro publicado en el año de 1761. Aunque en estricto sentido no es una normativa, representa un texto de importancia mayor, toda vez que contiene elementos de la Recopilación de Castilla, este sí, un cuerpo normativo; pero lo que hace más interesante la obra es que se comenta la pertinencia de esa normatividad existente para la realidad novohispana.

Por otro lado, se encuentran Las Ordenanzas de Minería de 1783, las mismas que vieron la luz gracias al poderoso influjo del gremio minero encabezado por Joaquín Velázquez de León y Juan Lucas de Lassaga; lo importante de estas Ordenanzas de corte monárquico es que a lo largo del siglo XIX se modificaron paulatinamente, sin abrogarlas, adaptándolas de manera constante a las nuevas necesidades del Estado-nación en ciernes.

En tercera instancia está El Código Minero Mexicano de 1884, que representa un espíritu de quiebre entre el orden antiguo y una nación que se piensa y se entiende como moderna, aunque, aparentemente, el cambio es solo nominal y no de contenidos; es pues apenas una transición lo que se contiene en este código.

Finalmente, como representante de la idea porfiriana de progreso y liberalización tenemos a La Ley Minera de los Estados Unidos Mexicanos de 1892. Estas normativas antes mencionadas son el eje central para analizar las dos funciones que marcarán las rupturas y permanencias a que se hizo alusión en el título. Hay, sin embargo, también algunas referencias indirectas a lo largo del texto, contenidas en trabajos de análisis sobre derecho indiano y minero.

\section{¿Quién es justicia y quién gobierno?}

Probablemente la pregunta pertinente que sirva de hilo conductor a este primer momento en realidad debería ser: ¿de qué manera ocurrió el trasplante de normatividad peninsular, en especial castellana, hacia América y qué ocurrió con ella de cara a los nuevos tiempos del siglo XIX? Una respuesta general nos dirá que la fusión de las costumbres locales con el derecho castellano dio lugar a un impresionante cuerpo casuístico para normar criterios en las distintas esferas de la vida novohispana. Hay que explorar pues la aseveración general en sus rasgos particulares teniendo como ventana a la administración de justicia $\mathrm{y}$ al gobierno en materia minera.

¿Quién ejercía, por cierto, esas funciones a mediados del siglo XVIII en la Nueva España? Hay una larga e interesante discusión precisamente en torno a 
la administración de justicia y al gobierno, tanto en la península como en tierras americanas; según algunos autores, desde el siglo XIII, en la península se estaba pensando en la separación de justicia con respecto al gobierno, lo cual no implica que efectivamente hubiese de manera generalizada una práctica homogénea al respecto. Por lo tanto, al menos de manera teórica, se notaba un interés por la diferenciación de funciones, de tal suerte que para el siglo XVIII no era simplemente una preocupación inasible, sino parte de una nueva concepción del Estado el separar funciones, para evitar que una sola persona pudiese aglutinar demasiado poder en su mano y con ello "abusar de su autoridad" 3.

Pese a esta preocupación, evidentemente el traslado de instituciones y normas castellanas hacia la nueva realidad americana no implicó que se implantaran todas las instituciones y prácticas de manera idéntica. Al contrario, la cosmovisión hispana tuvo que adecuarse a ciertas condicionantes geográficas, de diversidad cultural y, sobre todo, a la enorme distancia física entre la metrópoli y sus colonias, de tal suerte que se fusionaron ideas y formas de entender la vida social, generando eso que a la postre se denominaría Derecho Indiano ${ }^{4}$.

El problema de una rápida expansión hispana hacia los territorios conquistados en América implicó, en ocasiones, que hubiese cierta carencia de autoridades letradas en representación del rey, pero, a la vez, esa expansión creaba la necesidad de control político, razón por la cual, en muchas ocasiones se encargaba a una misma persona tanto administrar justicia como ejercer la policía o el gobierno en algunos lugares, sobre todo en los más alejados del centro. En cuestión de justicia, por ejemplo, en Nueva España la primera instancia que tenía conocimiento de los asuntos litigiosos eran los alcaldes mayores; después, las Audiencias, ya fueran la de Guadalajara o la de México, y en suprema instancia, el Tribunal de Indias. El problema era que, precisamente, en lugares alejados rara era la ocasión en que existían todas las autoridades establecidas y de acuerdo a ello, a la de mayor rango se le asignaban varios cargos a la vez; de esa manera, el título de corregidor o alcalde mayor o gobernador con el tiempo se fue volviendo una especie de sinónimo, aun cuando estaban especificados como cargos distintos: el alcalde mayor, por ejemplo, se consideraba como un juez de apelación de primera instancia con jurisdicción regional, mientras que el corregidor era un oficial real a nivel municipal, con atribuciones gubernativas, pero además

\footnotetext{
3 En el antiguo régimen no se mencionaba la idea de "corrupción"; esta se generalizaría más tarde y tenía como rasgo más bien a un proceso de "descomposición" o deterioro, imputado a la realidad americana. Para el caso, lo que sí aparecía en distintos ámbitos de la impartición de justicia era precisamente el asunto del "abuso de autoridad".

4 Sánchez Bella, Ismael, Derecho Indiano, España, Universidad de Navarra, 1991.
} 
con cierto estatus superior al del alcalde mayor ${ }^{5}$. La necesidad de expandir las funciones de un alcalde mayor en un territorio alejado fue lo que originó que en el XVIII se considerasen cargos equivalentes.

De un tipo especial de gobierno, por ejemplo -y en lo que toca al interés más particular de este trabajo- se ocupaban las diputaciones mineras, que eran en realidad representantes de mineros en activo, de ahí que se les considerase diputados precisamente ${ }^{6}$; podían hacer registros de denuncios de minas, tramitación de pleitos ante la justicia correspondiente y control hacendario de ingresos de la Corona. Para ser diputado minero se necesitaba, evidentemente, ser un señor de minas y además tener el estatus de vecino. Las diputaciones carecían de funciones jurisdiccionales reconocidas, sin embargo, hubo lugares en los que el corregidor delegaba funciones de consultoría en litigios judiciales al cabildo de diputados mineros y mancomunaba las responsabilidades en los fallos ${ }^{7}$. Hacia el siglo XVIII, las diputaciones mineras habían formado "cabildos" en algunos lugares, que controlaban, por ejemplo, el abasto de carne en los reales de minas y hasta manejaban como propios el producto de las obligadas de carnicería.

Hay que resaltar que incluso en reales de minas muy nuevos, donde se carecía de letrados o gente de "capa y espada" para la administración de justicia ordinaria, la diputación minera ejercía funciones de justicia y gobierno más allá incluso de la jurisdicción privativa minera, siempre y cuando no hubiera -insisto- ni un alcalde mayor o un corregidor ${ }^{8}$. Para complicar las cosas, la minería no formaba parte de la justicia ordinaria, sino que se consideraba al lado del ejército o la iglesia como jurisdicciones privativas. De acuerdo a ello, el encargado de la justicia minera sería un Alcalde Mayor de Minas, separado totalmente del ordinario y que únicamente operaría en asuntos mineros; el problema era que casi nunca había un justicia de minas y un ordinario en sitios donde con dificultad había autoridades religiosas, quienes, hay que decirlo, in absentia de justicias reales tenían que asumir funciones de gobierno y justicia.

5 Piña Homs, Román, “Ordenanzas para corregidores y alcalde mayores dadas por las autoridades indianas", Memoria del X Congreso del Instituto Internacional de Historia del Derecho Indiano, Tomo II, México, Escuela Libre de Derecho/UNAM, 1995, p. 1206.

${ }^{6}$ La noción de antiguo régimen para diputado es solamente la de representante, sin ninguna función más allá que la de representar. Con el desarrollo de los procesos modernizantes, el diputado fue ampliando sus potestades.

7 Enciso, José, "La diputación de minas en Zacatecas en el siglo XVI", Memoria del X Congreso de Historia del Derecho Indiano, Tomo I, Parte 2, México, Escuela Libre de Derecho/ UNAM, 1995, p. 453.

8 Mecham, Lloyd, "The Real de Minas as a political institution in Spanish colonial America", Hispanic American Historic Review, vol. II, N 7, 1927, pp. 45-83. 
Por todo lo anteriormente dicho, es evidente que no existió durante buena parte de la Colonia una demarcación fuerte entre la administración de justicia y el gobierno en materia minera, por más que en términos discursivos se tratara de regular; la respuesta entonces a la pregunta de quién ejercía cada una de las funciones deberá ser matizada por caracteres regionales y por las formas que consuetudinariamente se fueron estructurando. De esa manera, se podían encontrar funciones de gobierno y justicia en quien solo debería ejercer las primeras y viceversa.

Lo anterior nos sirve entonces para decir que probablemente estemos ante las formas de gobierno y justicia en el antiguo orden y que los aires ilustrados, primero, y los liberales, después, vendrían a darle a estos aspectos una fisonomía radicalmente distinta, en donde se estableció una demarcación más o menos definitiva entre las dos funciones.

\section{Normatividades en justicia y gobierno mineros}

Cuando el notable jurista novohispano Francisco Xavier de Gamboa ${ }^{9}$ redactó su obra Comentarios a las Ordenanzas de Minas, estaba llamando la atención a varios problemas palpables en Nueva España; uno de ellos tal vez de primer orden era precisamente el asunto minero y su normatividad. Concluyó ahí que la legislación minera existente era el fruto de las leyes castellanas, pero también de la práctica minera local, razón por la cual se tenía que pensar en ella como fundamento de orden, toda vez que representaba a la realidad circundante.

Las Ordenanzas que comentaba en su texto Gamboa eran las contenidas en la Recopilación de Castilla u Ordenanzas del Nuevo Cuaderno, en la materia referente a tesoros y mineros, ordenanza LXVXVII. Si en las páginas precedentes traté de mostrar breve y escuetamente qué sucedía con los aspectos de gobierno y justicia, hay la necesidad de acudir entonces a una exploración más cercana de la aplicación de normas castellanas a la actividad minera para detectar el paulatino cambio que sufrieron en distintos contextos sociales e históricos.

9 Gamboa fue todo un personaje en la vida novohispana del momento; se decía de él que era tan grave jurisconsulto como notable geómetra y conocedor minero. De ascendientes vizcaínos, Gamboa fue consultor del Consulado de Comercio, alcalde del crimen de la Real Audiencia de México, oidor, hasta llegar a presidente de la misma, a la vez que ocupó un puesto en la Audiencia de Barcelona y en la Real Audiencia de Santo Domingo, entre otros puestos. Educado por jesuitas y profesante del naciente patriotismo criollo, se opuso con toda energía a las reformas planteadas por los borbones, llegando a enemistarse con Joseph de Gálvez y con el Marqués de Croix, entonces virrey de la Nueva España. 
Como sabemos, la minería era regida por lo contenido en la Recopilación de Castilla, pero además, por las ordenanzas emitidas a lo largo de toda la colonia, algunas de carácter local, regional o provincial, pero ninguna con carácter de general y aplicable en toda Nueva España.

Tomando en cuenta que el orden de prelación establecía acudir primero a las leyes castellanas para dar orden a los asuntos mineros, Gamboa se encargó de analizar la pertinencia de los contenidos y sugerir, gracias a su experiencia, algunas propuestas. En lo tocante a las cuestiones de gobierno y justicia, la Recopilación decía a la letra que

una de las cosas que impide la buena orden (sic) y beneficio de las minas, que al presente están descubiertas, y que no se busquen, ni se descubran otras de nuevo, es los pleitos, y debates, que en ellas y entre la gente que en ellas anda y trabaja, se ofrecen y las molestias y vejaciones, que los justicias, y otras personas hacen a los Ministros y Trabajadores, que en ellas andan, así por no tener las dichas Justicias la práctica y experiencia que conviene en negocios de Minas, como proceder en las Causas larga y Ordinariamente ...habemos acordado nombrar un Administrador General y los demás Administradores que fueren menester por los Partidos y Distritos... las cuales tengan el Gobierno y la Jurisdicción de todas las dichas Minas y cosas a ellas tocantes, y sean superiores a las demás personas... los cuales tengan jurisdicción para conocer en primera instancia de todos los pleitos y causas y negocios civiles y criminales... y mandamos a las nuestras Justicias así Ordinarias como de Hermandad y de Comisión y otras cualquier de estos nuestros Reinos que no se entrometan en el conocimiento de las dichas causas tocantes y concernientes a las dichas minas...

Los Comentarios de Gamboa respecto a los contenidos de esta disposición fueron varios: uno de ellos es que la dilación en el descubrimiento de minas y nuevos denuncios no se solucionaría con jurisdicción privativa, ni con el nombramiento de administradores generales y distritales, dado que los mineros serían agraviados al mantener a su costa dichos administradores. Gamboa dijo que lo que retrasaba las cuestiones antes mencionadas, así como los litigios mineros, era la presencia de "partes" o "apoderados", que alargaban a propósito los juicios con el fin de obtener mejores remuneraciones, razón por la cual propuso se les excluyera de los litigios en minas. De igual manera, planteó mantener como primera instancia judicial a los corregidores o alcaldes mayores ordinarios y como segunda, a las Audiencias, pero a la vez, que la propia Audiencia nombrara a un visitador, versado en asuntos mineros, para revisar el buen gobierno de los asientos mineros, es decir, lo referente a abasto de azogue o a las técnicas de beneficio, entre otras cosas, pero: 
debe advertirse que si sobre otros puntos de contratos de compra o venta de minas o sucesión de ellas por testamento o en otra forma se moviere pleito, no sólo es competente el Juez Mayor de Minas, sino las otras justicias ordinarias de aquel territorio: y sólo en lo que concierne a puntos de Ordenanzas es primero el juez de Minas, y por su falta las demás justicias... ${ }^{10}$,

aunque como hemos visto, casi siempre había falta de juez de minas y se delegaba esa función en los jueces ordinarios.

A final de cuentas, si bien es cierto que los Comentarios de Gamboa se publicaron con aprobación y privilegio del rey, este último no movió un dedo para hacer efectivos los consejos de Gamboa; una de las razones de ello fue que Gamboa se opuso enérgicamente al proceso reformista borbón, pero, sobre todo, porque era representante de una de las corporaciones que mayor poder económico tenían a la época, como lo era, sin duda, el Consulado de Comercio, el mismo para el que Gamboa solicitaba en sus Comentarios el control de la actividad minera. En lo tocante al gobierno y la justicia, Gamboa puso de relieve algunas cosas notables: se observa en todo caso que para entonces, a mediados del siglo XVIII, ya se tenía la inquietud de separar las atribuciones gubernativas de las judiciales. La apuesta de personajes como Gamboa era que la división de potestades al respecto, en este caso los mencionados, tendría eventualmente que abrir nuevos espacios políticos mediante los cuales comenzar a ejercer el autogobierno a manos de criollos, solo que ese es otro tema.

Lo interesante es que la corona española no solo prestó oídos sordos a las propuestas del Consulado de Comercio, representadas ampliamente en la obra de Gamboa, sino que operó incluso de manera inversa. Me explico: en uno de los apartados, Gamboa decía que los mineros eran incapaces de administrar la propia minería, dada su "tendencia al lujo, la superfluidad y la vanidad", por tanto, los únicos capacitados para la empresa eran los miembros del Consulado de Comercio. Si Gamboa no les concedía a los mineros capacidades gubernativas, mucho menos lo hacía con las judiciales. Evidentemente, para la corona el dotar de jurisdicción al Consulado de Comercio implicaba ampliar su poder económico a un poder también político y, precisamente, uno de los objetivos del

${ }^{10}$ Gamboa, Francisco Xavier de, Comentarios a las Ordenanzas de Minas, dedicados al católico rey nuestro Señor D. Carlos III (que Dios guarde) siempre magnánimo, siempre felíz, siempre augusto, por Francisco Xavier de Gamboa, Colegial de el Real y más antiguo de San Ildefonso de México, Abogado de la Real Chancillería de aquélla ciudad, y de presos del Santo Oficio de la Inquisición, su consultor por la Suprema, y Diputado del consulado y Comercio de Nueva España en la Corte de Madrid. Con aprobación y privilegio del Rey, Madrid, Oficina de Joaquín Ibarra, 1761; edición facsimilar, México, Miguel Ángel Porrúa, 1987, p. 472. 
proceso reformista borbón era destruir células autónomas de poder, aplicando en ocasiones una estrategia de pesos y contrapesos.

La respuesta de la corona entonces fue la siguiente: concedió que el gremio minero se erigiese como un cuerpo con reconocimiento real, es decir, en una corporación con derechos y obligaciones, que se opusiera con tales armas al poder del Consulado de Comercio ${ }^{11}$. El proceso es ciertamente más complejo que eso, pero para los fines que nos tocan hay que decir que el rey incentivó dos cosas fundamentales en la lógica de pesos y contrapesos: una de ellas fue la facultad a los mineros de formar un Real Tribunal de Minería, en 1777, compuesto por mineros y no por letrados; la otra fue confeccionar de una vez y para todas unas ordenanzas "modernas" 12 que rompiesen con la casuística y que fuesen válidas lo mismo para los minerales del norte que para los del centro.

La noción de "moderno" es un elemento adicional de interés, y me parece que hace referencia precisamente al rompimiento de ciertos valores tradicionales, que a partir de ahí se ubican como viejos. Veremos si así sucedió en efecto. Encabezados por Joaquín Velázquez de León y Juan Lucas de Lassaga, ambos prominentes mineros y juristas -sobre todo el primero- los mineros y su flamante Tribunal se lanzaron a confeccionar las Ordenanzas que sancionaría el rey ${ }^{13}$. No se les concede todo lo que solicitan en el proyecto ${ }^{14}$ elaborado por ellos, sin embargo, se marcaron algunas diferencias con respecto a los contenidos reseñados por Gamboa anteriormente que, dicho sea de paso, jamás aprobó -ni colaboró- con el Tribunal.

Finalmente, en 1783 el rey aprobó -con modificaciones-y expidió las Reales Ordenanzas ${ }^{15}$ que habrían de regir la actividad minera y cuyos rasgos más importantes en lo referente a la justicia y gobierno se incluyen en el Título $1^{\circ}$ :

${ }^{11}$ Brading, David, Mineros y Comerciantes en el México Borbónico, México, FCE, 1974.

${ }^{12}$ Así lo dice en el texto original y con ello enfatiza doblemente el asunto de la ruptura de valores arcaicos.

${ }^{13}$ Un interesante seguimiento de las Ordenanzas, desde que eran un proyecto hasta que las sanciona el rey, lo hace María del Refugio González, vid. supra.

${ }^{14}$ Se conoce como el Proyecto a las Ordenanzas que elaboraron los miembros del Tribunal Minero y que posteriormente remitieron al rey para ser sancionado y aprobado.

15 "Reales Ordenanzas para la dirección y régimen de gobierno del Importante Cuerpo de la Minería de Nueva España y de su Real Tribunal General del orden de su Majestad”, contenidas en Ordenanzas de minería y colección de órdenes y decretos de esta materia posteriores a su publicació , a las que van agregadas las reformas de que son susceptibles algunos de los artículos vigentes de las mismas Ordenanzas con un apéndice concerniente a las mismas del Perú, París, Ch. Bouret, 1875. 
Concedo al Real Tribunal General de la Minería el que pueda conocer y providenciar en todos los negocios pertenecientes a su cuerpo en lo gubernativo... y en su consecuencia declaro que las diputaciones de todos los Reales o asientos de Minas han de reconocerle una precisa e inseparable subordinación en todas las indicadas materias puramente gubernativas... el Director General (del Tribunal) tendrá voto en todos los negocios directivos, gubernativos y económicos cuyo conocimiento va concedido al Real Tribunal General de México... pero declaro que no lo ha de tener en sustanciación y determinación de los pleitos y litigios ${ }^{16}$. Además han de ser del privativo conocimiento del Real Tribunal las causas sobre descubrimientos, denuncios, pertenencias, medidas, desagües de Minas y todo lo que se hiciere en ellas en perjuicio de su laborío y contraviniendo a estas Ordenanzas... pero declaro que la mencionada jurisdicción contenciosa sólo la ha de ejercer dicho Real Tribunal General en el distrito de veinte y cinco leguas en contorno de la capital de México.

Si perjuicio de la privativa jurisdicción gubernativa que concedo al referido Tribunal, podrán las Diputaciones de los Reales de Minas usarla y ejercerla en sus respectivos territorios... procurando los diputados el provecho, progreso, laborío y buena administración de justicia en las minas...

Será privativa de las Diputaciones territoriales en sus respectivos distritos la jurisdicción contenciosa...procediendo y determinando en ellas con absoluta independencia del mismo Real Tribunal, pues el ejercicio de tal jurisdicción contenciosa de ninguna manera la han de reconocer subordinación alguna por quedar, como quiero quede, inhibido el dicho Real Tribunal de introducirse a conocer ni a mezclarse en dichas causas y juicios suscitados fuera de su Distrito... ${ }^{17}$.

El análisis de las diferencias entre el proyecto presentado por el Tribunal y las Ordenanzas aprobadas por el rey rebasa con mucho los objetivos de este trabajo, pero me parece pertinente señalar al menos que en el dicho proyecto el Tribunal proponía una jurisdicción contenciosa privativa a los asuntos mineros de Nueva España, es decir, gobierno y justicia de cuantos litigios hubiese en todos y cada uno de los asientos mineros. Evidentemente, la concepción de la Corona iba en el sentido de hacer primero una separación efectiva de justicia y gobierno, y por otra parte, otorgar nuevos espacios de poder pero con limitaciones para no perder el control ni fomentar el autogobierno, aspiración además muy criolla y muy del siglo XVIII.

Lo notable en las Ordenanzas es que los Diputados Mineros pasaron de ser una especie de apoderados o representantes sin reconocimiento legal de gente

16 Título 1, apartado 1 de las Ordenanzas de 1783.

${ }^{17}$ Títulos $2^{\circ}$ y $3^{\circ}$, apartados 2 y 3 . 
dedicada a la actividad minera, a constituirse, de hecho, en los depositarios de la justicia privativa minera; abandonaron de esa manera casi por completo las actividades gubernativas, es decir, tomaron el lugar del antiguo Alcalde Mayor de Minas. Contrario a la apuesta de quienes formaban el Real Tribunal, a ellos solo se les asignaron características puramente gubernativas en materia minera y una jurisdicción judicial muy reducida, sin capacidad de participación en los asientos mineros de mayor importancia, aunque tenían bajo su responsabilidad, por ejemplo, el Colegio de Minería o el Banco de Avíos, asuntos de categoría también mayor.

Las Ordenanzas de 1783, cotejadas con las de la Recopilación que comentaba Gamboa, nos pueden mostrar que se mantuvo la jurisdicción privativa minera, es decir, la capacidad de resolver los litigios entre mineros de manera autónoma con respecto a la justicia ordinaria ${ }^{18}$; sin embargo, la ascensión de nuevas figuras jurídicas y cargos abrió la posibilidad de establecer una diferenciación más efectiva entre justicia y gobierno en materia minera. Al lado de esas cuestiones de forma hay que reparar en las de contexto: no puedo saber en este momento si la separación de funciones se llevó a cabo de manera total o tan siquiera cercana; me parece que se operó de la manera más o menos establecida en las Ordenanzas. En lo que se debe reparar es en el carácter más simbólico de las Ordenanzas como vehículo que equipara las reglas de juego para la actividad minera, haciendo un parteaguas entre la normatividad o normatividades provenientes de la etapa medieval europea y, del otro lado, el casuismo y posterior homogeneización como aspiración inherente en las Ordenanzas de 1783, pero que aún no incorpora las inquietudes más decimonónicas y liberales. En todo caso, hablamos de antiguo régimen, un antiguo régimen que al menos en materia minera -y teniendo como paradigma la legislación- desaparecerá solo hasta los últimos años del siglo XIX.

Evidentemente pues, la llegada del siglo XIX y el nacimiento del liberalismo no quebraron el viejo orden de un día para otro, ni mucho menos. Pese incluso a la revolución de independencia, las normas, las estructuras sociales y muchos otros elementos mutaron de manera lenta, entorpecidos aún más por la violencia del decimonono mexicano.

En términos de legislación minera, los cambios habidos prácticamente fueron nimios, toda vez que se conservaron las Ordenanzas del siglo XVIII, aunque no exentas de salvedades: por ejemplo, se consideraba que el regalismo,

${ }^{18}$ Mannori, Luca, “Justicia y Administración entre antiguo y nuevo régimen”. En Romanelli, R., Magistrati e poterree nella storia europea, Bologna, 1997, p. 17. 
de hecho fundamento de la normatividad existente, no era más la base para la posesión del suelo y de los recursos minerales, por tanto, a raíz del movimiento de Independencia y con la nueva idea sobre la nación mexicana, las propiedades pasaron de manos del rey al dominio directo de la nación.

Durante el largo siglo XIX, los cambios y resistencias se sucedieron de manera paulatina, en ocasiones gracias al influjo del liberalismo y en otras, a instancias de vientos conservadores. Un ejemplo de ello tiene que ver con la aspiración de lograr la participación de extranjeros y de sus capitales en distintas actividades económicas, una necesidad perentoria, a decir de muchos. El caso es que con las Ordenanzas coloniales se restringía a los extranjeros lo posibilidad de poseer y trabajar minas, toda vez que las Leyes de Indias les prohibía, incluso, habitar en la Nueva España. A mediados del XIX, aún estando vigentes las Ordenanzas de 1783, se modificó esa restricción y con ello se posibilitó que los extranjeros pudiesen participar como consocios, es decir, como la parte que podría dotar de capital a una negociación minera, aunque sin la capacidad de mantener posesión de fundos mineros.

Esta modificación liberalizó de manera parcial la actividad minera y, como apuntamos, parecía incentivar a que los capitales extranjeros aportaran fondos para reactivar la actividad económica; sin embargo, esta "liberalización cosmética" ${ }^{19}$ no fue suficiente para incrementar el nivel de las operaciones o generar de manera efectiva un proceso dinámico en la minería. El asunto era demasiado complicado para los inversionistas extranjeros, quienes tenían tras de sí claramente una amarga experiencia, como el caso de los ingleses ${ }^{20}$, y la medida no generaba la confianza necesaria para que los extranjeros se arriesgaran a ser solamente consocios.

De cualquier manera, muchos de los decretos que modificaban, abrogaban o mejoraban las antiguas Ordenanzas resultaron ser letra muerta; la violencia del siglo XIX dejó pendientes muchas asignaturas de la vida social y política. Más que soluciones, los procesos normativos se constituyeron en visiones y aspiraciones, salidas teóricas a problemas que requerían un poco más de

${ }^{19}$ El término de "modernización cosmética" es referido por Bradford Burns en su trabajo The Poverty of Progress. Latin America in the Nineteenth Century, Berkeley, University of California Press, 1980. Con ello, el autor refiere que las élites asumen un discurso de cambio, pero en la práctica ese discurso solo sirve para legitimar una posición que en realidad les permite no cambiar. Es pues casi una paradoja.

${ }^{20}$ El caso más conspicuo está en Ward Henry, México en 1827, México, Fondo de Cultura Económica, 1981. Ahí el autor relata de qué manera es comisionado por la corona inglesa para visitar México en el periodo posterior a la Independencia; el caso es que su balance refleja un estado de desastre para los intereses británicos en la nueva nación mexicana. 
pragmatismo. No sería sino hasta la última parte del siglo cuando hubo la calma -tensa pero calma- para ensayar ajustes en el rumbo y proyecto de nación.

La minería, como actividad, seguía siendo un elemento de importancia mayor a fines del siglo XIX y por ello pronto se hizo patente la necesidad de un código "moderno" 21 que permitiera un manejo "científico" y "liberal" de la actividad minera, que además sirviera como pivote para el desarrollo económico a otras actividades productivas, como la ganadería y la agricultura. Los códigos, en la concepción liberal, estaban llamados a romper con las normatividades donde el sujeto de derecho eran las corporaciones y no los individuos. De esa manera, el proceso codificador de corte liberal en América Latina implicó la entrada del individuo en el derecho por sobre la calidad racial ${ }^{22}$.

Un código, por tanto, en la acepción moderna, es una ley y no una recopilación de leyes ${ }^{23}$; es, además, la normatividad homogénea y uniforme de una materia, un cuerpo que ha agotado la discusión teórica en torno a un problema. Representa, entonces, la racionalización de las normas que de manera concisa y precisa reúne brevemente todo lo relativo al tema en cuestión. Prescinde por necesidad de todo lenguaje excesivo, no describe sino define.

En esa perspectiva nació el Código de Minería de $1884^{24}$, que para los asuntos gubernativos y judiciales estipulaba:

El ramo de minería, en lo gubernativo y económico dependerá del Ministerio de Fomento y de los funcionarios o autoridades subordinadas al mismo, conforme a esta ley, y en lo contencioso corresponde el conocimiento de los negocios de minas a los jueces y tribunales respectivos de cada localidad.

${ }^{21}$ Entrecomillo moderno para llamar la atención sobre el hecho de que un siglo después de que se expidieran las Ordenanzas coloniales, la petición de un código tenía como justificación el mismo principio, es decir, la dotación de un cuerpo jurídico que estuviera acorde a lo moderno. Ello implicaba entonces homogeneización en el siglo XVIII, y a finales del XIX tenía el mismo carácter. Sin embargo, la etapa de codificaciones en América respondía a un afán inherente al lenguaje científico, el progreso como tránsito y el orden como fin, de tal suerte que las alusiones a lo "moderno" se calibran de distinta manera sin duda.

${ }^{22}$ Carmagnani, Marcello, "Instituciones financieras nacionales e internacionales del orden liberal mexicano, 1868-1911”. En Marcelo Carmagnani (coord.), Constitucionalismo y orden liberal en América Latina 1850-1920, Torino, Italia, Otto Editore, 2000, pp. 317-318.

${ }^{23}$ Tomás y Valiente, Francisco, Manual del Derecho Español, Madrid, España, Editorial Tecnos, 1997, p. 465.

${ }^{24}$ Código de Minería de la República Mexicana sancionado el 22 de noviembre de 1884 y Reglamento para la organización de los Tribunales de Minería y Arancel para el cobro de Derechos y Honorarios, México, Imprenta de Clarke y Macías, 1885. 
En todos los distritos mineros en que fuere posible y se estimare necesario por el Ministerio de Fomento, se establecerán Diputaciones de Minería que deberán ejercer todas las funciones gubernativas y económicas que se les señalan por éste Código.

En los distritos que no pudieren establecerse las Diputaciones de Minería, desempeñará sus funciones la autoridad política local, con dependencia en el ejercicio de ellas, del Ministerio de Fomento ${ }^{25}$.

Al respecto, se puede notar una separación tajante entre ambas funciones: el Tribunal de Minería de raigambre colonial cede su espacio a la Secretaría de Fomento, Exploración, Minas y Colonización, que era una cartera de gobierno dependiente del titular del ejecutivo. Por su parte, la Diputación Minera perdió la capacidad de administrar justicia y se convirtió en una especie de delegación regional de la Secretaría de Fomento, con un énfasis particular en materia gubernativa. Por ello, los asuntos mineros dejaron de tener una jurisdicción privativa y a partir de entonces los jueces y tribunales ordinarios locales podían conocer y resolver cualquier litigio, aunque teniendo como base lo observado en el Código.

Si bien la Diputación Minera persistió, en cambio se hizo más nítida la separación entre las funciones de justicia y gobierno; en lo tocante a la participación de los extranjeros a que se hizo alusión antes, la intención liberalizante se notó con mucha mayor claridad. Al respecto, se eliminaron las restricciones que existían desde la Colonia y se permitió a los extranjeros igualdad de condiciones respecto de los ciudadanos mexicanos para poseer y explotar fundos mineros, con la única restricción, aunque de carácter general, de pagar los impuestos y observar de manera rigurosa lo estipulado en el Código.

Pese a todo, el Código de 1884 no constituyó un punto de quiebre respecto de las prácticas productivas mineras ni un cambio sustancial en la inversión extranjera. Era, como le denominó María del Refugio González, un "hombre viejo con un saco nuevo" y es que, a decir de quienes han trabajado la legislación minera, ello solo generó otros problemas ${ }^{26}$, como la confusión sobre el domino radical del suelo, así enunciado en el Código, que por omisión permitió al propietario de la superficie el disfrute del nuevo pivote energético mundial: el petróleo.

${ }^{25}$ Título II, artículos 18, 21 y 23.

${ }^{26}$ Sánchez Mejorada, Carlos, Notas sobre la evolución y tendencias actuales del derecho mexicano, México, Publicaciones de la Academia Mexicana de Jurisprudencia y Legislación, Correspondiente a la Real de Madrid, 1944, p. 13. 
En esas circunstancias, era evidente que hacía falta un golpe de timón para cambiar el rumbo de la minería mexicana y modificar la estructura administrativa con una normatividad fundamentalmente más radical, liberalizante y sencilla en sus contenidos. El 4 de junio de 1892 se decretó, con esa idea, la nueva Ley Minera $^{27}$, que se complementó con una Ley de Impuestos a la Minería el día 6 del mismo mes.

De esa manera se ratificaba la necesidad de contar con una sola legislación que abrogara todos los decretos y códigos generados por las instancias estatales y que, además, facilitara los procesos de registro y posesión de las minas, así como los litigios. En ello, el Estado adelgazaría las restricciones de carácter gubernativo, renunciando por vez primera a acotar las formas de trabajar los minerales y las haciendas de beneficio ${ }^{28}$, o el tamaño de las pertenencias mineras, por ejemplo, aunque, por otro lado, se centralizaron y "endurecieron"

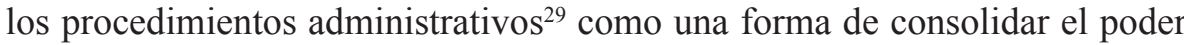
del Estado mexicano porfiriano.

La propiedad minera se adquiere originariamente de la Nación, mediante título expedido por el Poder Ejecutivo por conducto de la Secretaría de Fomento, previos el denuncio y demás requisitos establecidos por esta ley... ${ }^{30}$.

En la ley de 1892 no se incluyeron descripciones, contenidos o artículos de las funciones que tenía la Secretaría de Fomento, lo que implicó que lo que hasta ese entonces se denominaba gobierno se secularizara de la ley especializada en minas; esos procedimientos pasaron a ser parte de la estructura interna de la Secretaría de Fomento y de sus apéndices burocráticos ${ }^{31}$, estructura en la que no figuraría más, por cierto, el diputado minero, quien

${ }^{27}$ Ley Minera de los Estados Unidos Mexicanos, Guanajuato, Tipografía de la Escuela Industrial, 1909.

${ }^{28}$ Aunque conserva del Código de 1884 la potestad de cuidar el "buen orden en los trabajos en minas y Distritos mineros".

${ }^{29}$ Probablemente, las funciones y conceptualización de gobierno, como se ha visto, adquirieron una connotación de antiguo régimen, toda vez que abarcaban demasiados aspectos del proceso minero. Por tanto, se sustituyó la noción de gobierno por la de administración, mucho más específica y apegada a los valores liberales de la época.

${ }^{30}$ Capítulo VIII, artículos 107 y 110 de la Ley Minera de 1892.

31 "Reglamento para los procedimientos administrativos en materia de minería, 25 de junio de 1892”. En Dublán, Adolfo y Adalberto Esteva, Legislación mexicana o colección completa de las disposiciones legislativas expedidas desde la independencia de la República, arreglada por los licenciados Adolfo Dublán y Adalberto Esteva. Continuación de la ordenada por los licenciados Manuel Dublán y José María Lozano, Tomo XXI, México, Imprenta de Eduardo Dublán, 1898. 
cedería su sitio y funciones a un delegado regional de la propia Secretaría. A partir de ahí, el Agente de Minería, como se le denominó, sería la primera instancia administrativa, encargado de tomar conocimiento de denuncios mineros y, en su caso, de la concesión de títulos cuando así procediera, por no haber impedimentos o litigios en manos de los distintos juzgados de la federación que afectasen las propiedades contempladas en la solicitud vía el denuncio.

Las funciones de justicia, por su parte, quedarían, esas sí, contempladas en la ley:

Son competentes los Tribunales de la Federación, para conocer de los juicios que versen sobre los siguientes materias:

I. Oposición a denuncios o a expedición de títulos mineros

II. Oposición a rectificación de títulos o de localización de pertenencias tituladas

III. Nulidad de títulos mineros

IV. Expropiación por causa de explotaciones mineras

De los juicios criminales conocerá el juez que ejerza jurisdicción en el lugar de la comisión del delito...

Persistió, al igual que en el Código de 1884, el concepto de desaparecer las jurisdicciones contenciosas privativas y someter los litigios al conocimiento de los juzgados ordinarios; de esa manera, se combatían los procedimientos diferenciados y se homologaba la impartición de justicia.

\section{Conclusión}

La separación de las funciones de gobierno y justicia en materia minera fue posible a instancias del discurso liberal y a una serie de procesos de secularización que pretendieron enterrar a un antiguo régimen, aunque este resistió prácticamente durante todo el siglo XIX. La transición de ese mundo viejo a uno nuevo es un proceso de múltiples dimensiones, que va del modelo despótico ilustrado al criollismo, pasando por las juntas patrióticas, la independencia, la república, las reformas y, finalmente, el porfiriato. Todo ello terminó por dar a la administración de justicia y a las funciones gubernativas, en la actividad minera, calidad o calidades diferentes, sobre todo ante la discusión de la base soberana que habría de seguir, primero, la colonia hispánica, la nación recién independizada o el nuevo Estado-nación mexicano. Esas bases de poder definían, por tanto, en las diferentes normatividades las características de la propiedad minera como cosa del rey, con una base regalista, o bien, propiedad de la nación, con una base republicana. 
Los cambios de idea sobre quién y de qué manera habrían de ejercer las funciones de justicia y gobierno para ordenar la actividad minera deterioran ciertamente los valores de antiguo régimen, como parte de una aspiración por racionalizar y reestructurar las sociedades en su camino al mundo "civilizado". Sin embargo, no se puede hablar, me parece, de una quiebre brutal de ese antiguo régimen, toda vez que el siglo XIX mexicano tuvo una enorme participación política de quienes trataron de estructurar la nueva nación sobre la base de valores y estructuras provenientes del mundo colonial.

Las características de esa separación de funciones tiene como primer elemento al lenguaje: las dos primeras legislaciones enumeradas, la Recopilación de Castilla y las procedentes del Real Tribunal de Minería, están pensadas y ejecutadas en un lenguaje clásico y barroco a la vez, llenas de citas del derecho romano y castellano; el Código de 1884 y la Ley de 1892 hace alusión al lenguaje simple, exacto y preciso de la ciencia.

Por otra parte, el cambio de espacios jurisdiccionales y potestades, así como actores, llevó a desenmarañar una práctica de reglamentar, vigilar y ordenar la actividad minera a manos de una sola instancia, para diferenciarla y hacerla menos subjetiva; me explico: si en la Nueva España un diputado minero podía generar normas, representar a un cuerpo de mineros y dirimir un conflicto por propiedades mineras, sobre la base de un derecho corporativo privativo, además en nombre del rey, por el contrario, a fines del siglo XIX ya no existía el diputado minero, la justicia la ejercía un juez ordinario, los procesos de reglamentación y administración los ejecutaba una Secretaría que dependía del ejecutivo, pero que obraba como instancia secular. Luego entonces, efectivamente la madeja se desenredó.

Los valores inmiscuidos en este proceso histórico son, sin duda, valores que tienden a la construcción de un Estado moderno y, por tanto, representan una modernización de las funciones de justicia y gobierno en materia minera; sin embargo, me parece que se debe ver como un proceso paulatino de cambio y no como violenta irrupción; tal vez, entonces, para afinar estas percepciones haga falta un complemento que descanse en la práctica contenciosa o litigante para comprender mejor el cambio y la resistencia. 